\title{
siam
}

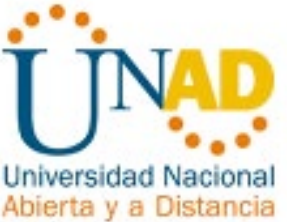

\section{THE ROLE OF ECONOMIC COOPERATION BETWEEN TWO RURAL COMMUNITIES}

Jorge Amador Moncada

PhD. Researcher.

Humboldt Institute. Bogota D.C - Colombia

jamador@humboldt.org.co

Johan Manuel Redondo

PhD. Researcher.

Humboldt Institute. Bogota D.C - Colombia

jredondo@humboldt.org.co

Gerard Olivar Tost

PhD. Professor.

National University of Colombia. Manizales - Colombia

golivart@unal.edu.co

\section{ABSTRACT.}

Historical civilizations have evidenced different routes to the collapse mainly due to political, warfare, cultural and environmental damages. This has animated modern researches to study and understand social, economic, and environmental challenges that modern societies must adopt in order to avoid history from repeat itself, and even worst, irreversibly. Many of these researches are focused on modelling through sets of ordinary differential equations (ODE's) representing the dynamic interaction between natural resources and population in an isolated society. In this work, we introduce the fact of cooperation between two similar societies, modelled as sets of ODE's of the type Brander and Taylor (1998), in the sense that economical exchange can exist between them. We couple two societies by introducing a simple receive-and-protect rule in which one society receive the other's help under the condition of protecting its own resources. We set that this cooperation may 


\section{Sijgm}

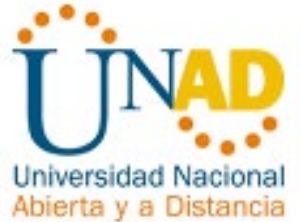

be constant, when it does not change all over the time, or changes intermittently depending on the level of resources each society has at any time. When cooperation is constant, the resulting system is a 4-dimensional system of ODE's that evolves smoothly, but if cooperation is intermittent, the coupled 4-dimensional system becomes a Filippov system. In both cases, we found that under economic cooperation, societies can survive at least in the long run, different from what happens when both societies are treated in isolation for the same parameter values.

\section{Keywords}

Sustainability; Cooperation; Filippov system

\section{Introduction}

There is currently a lot of evidence that environment worldwide has been passed the ecosystemic boundaries mainly due to overexploitation of natural resource and overpopulation bringing as consequences: hungry and thirsty, migration, climate change, epidemics, and deforestation to name a few. To face these problems that concern us all, researches has been studying and understanding the dynamic processes of human-environment interactions of past societies worldwide that collapse either by political, social or environmental reasons in order to explain the route they followed and try to answer the question if modern societies are on a similar way and contribute to the decision making to avoid it.

Many of the available research dealing with populations and the way they used their natural resources are focused on mathematical modelling to qualify and quantify ancient civilizations that have followed the path to the collapse ( $\mathrm{J}$. Brander, 1998; Flores, 2015; Heckbert, 2013). Proposed models are mainly sets of ordinary differential equations related to the Lotka-Volterra model, 


\section{Sijem}

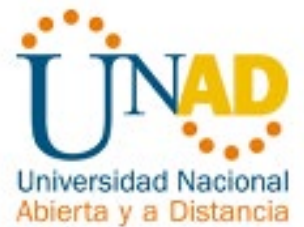

where population is the predator and natural resources represent the prey like Brander and Taylor's model (J. Brander, 1998). From this model, many adaptations with specific purposes have been developed but, just a few deals with the movement of population and products trade (D. Angulo, 2015; S. Roman, 2018). In this work we introduce and study the economic cooperation between two rural communities modelled as Brander and Taylor's type communities consisting of two sets of ODE's, so that in absence of cooperation both communities independently evolve, but once economical exchange is introduced into the system, flows of input and output appear and the two planar systems becomes a 4-dimensional one. Incoming flows besides being used for subsistence also reflect the engagement towards the protection of the resource. Namely, each community receive the other's help under the condition of protecting an equal amount of its own resources. We study the long-run effect of cooperation on the coupled system when it occurs not only constantly (smooth) but also intermittently (Filippov, 1988) over time.

\section{The model}

The coupled Brander and Taylor's type models is

$$
\left\{\begin{array}{l}
\mathbb{L}_{1}^{\&}=\left(C_{1} \phi_{1} \alpha_{1} \beta_{1} S_{1}+\left(1-C_{2}\right) \phi_{2} \alpha_{2} \beta_{2} S_{2}-\sigma_{1}\right) L_{1}, \\
\oiint_{1}^{\&}=\rho_{1}\left(\frac{S_{1}}{T_{1}}-1\right)\left(1-\frac{S_{1}}{K_{1}}\right) S_{1}-\alpha_{1} \beta_{1} L_{1}\left(S_{1}-S_{2 \rightarrow 1}\right), \\
\&_{2}^{\&}=\left(C_{2} \phi_{2} \alpha_{2} \beta_{2} S_{2}+\left(1-C_{1}\right) \phi_{1} \alpha_{1} \beta_{1} S_{1}-\sigma_{2}\right) L_{2}, \\
\oiint_{2}^{\&}=\rho_{2}\left(\frac{S_{2}}{T_{2}}-1\right)\left(1-\frac{S_{2}}{K_{2}}\right) S_{2}-\alpha_{2} \beta_{2} L_{2}\left(S_{2}-S_{1 \rightarrow 2}\right) .
\end{array}\right.
$$

Where $C_{1}, C_{2} \in[0,1]$ represent the portion of harvested resources taken for internal consumption, then, $\left(1-C_{1}\right)$ and $\left(1-C_{2}\right)$ are the percentages of outgoing resources from each community; $S_{1 \rightarrow 2}$ and $S_{2 \rightarrow 1}$ are the resources protected quantities defined as 


\section{Silizm}

$S_{1 \rightarrow 2}=\frac{\left(1-C_{1}\right) \phi_{1} \alpha_{1} \beta_{1} S_{1}}{\phi_{2} \alpha_{2} \beta_{2}}$

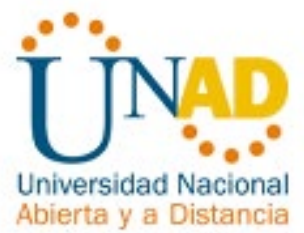

and

\section{Results}

Parameter values used for numerical computations are those reported in ( $\mathrm{J}$. Brander, 1998; D'Alessandro, 2007).

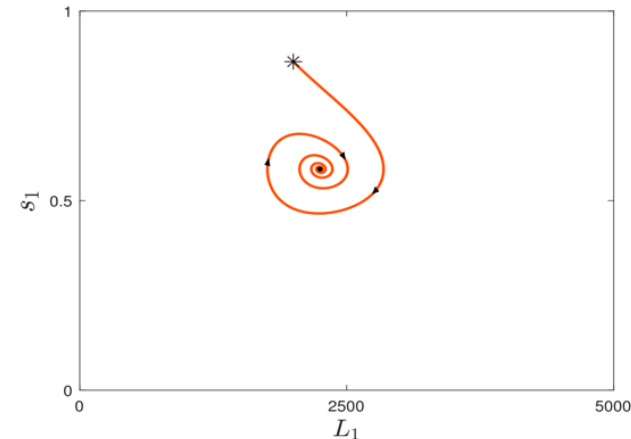

(a)

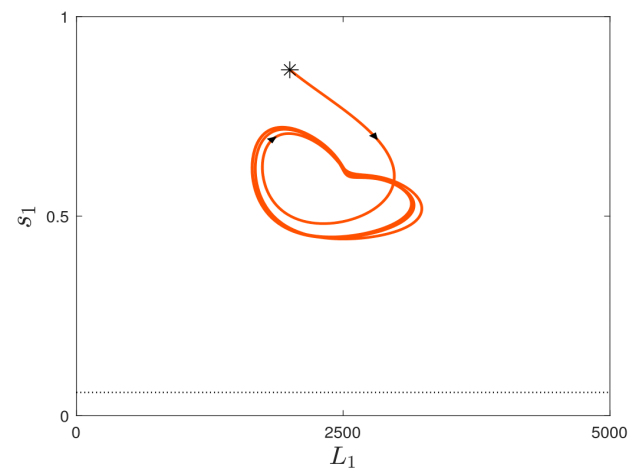

(c)

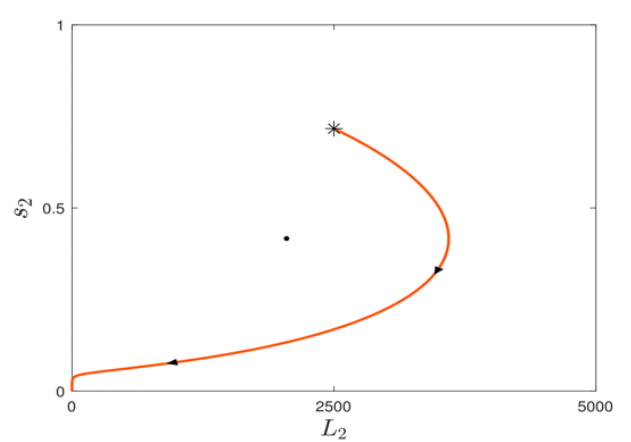

(b)

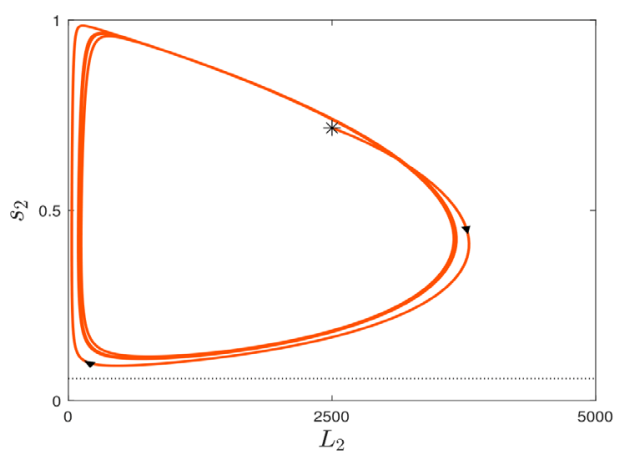

(d) 

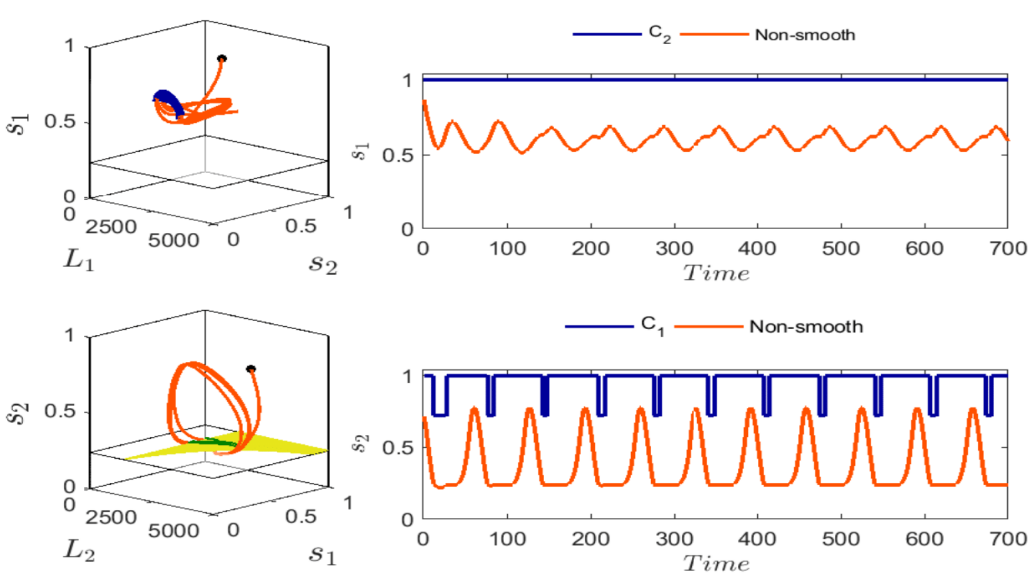

(e)

Figure 1: Outcomes for system (1) when considering different values of $C_{1}$ and $C_{2}$.

\section{Conclusion}

Figures 1(a) and 1(b) are numerical simulations of isolated communities, i.e. $C_{1}, C_{2}=1$. Under this condition, population of community 1 can live in harmony with environment without overharvesting their renewable resources (sustainable) but, community 2 exhaust its resources in the long run (unsustainable). For the same parameter values and initial conditions but considering the exchange of the $8 \%$ of the resources, namely, $C_{1}, C_{2}=0.92$, both communities falls into periodic solutions (invariant set). Despite this, neither community 1 nor community 2 exhaust completely their resources as shown in Figures 1 (c) and 1(d). Finally, if cooperation is a mutual decision that should be taken depending on the level of resources each community has at any time, system (1) becomes a Filippov system with sliding region as plotted in Figure 1(e). In both cases, the continuous and discontinuous, the movement of resources between communities has a positive effect on the long run since exhaustion is avoided. 


\section{Sijemt}

\section{REFERENCES}

- D. Angulo, F. A. (2015). Dunamics and forecast in a simple model of sustainable development for rural populations. Bulletin of Mathematical Biology, 77(2), 368-389.

- D'Alessandro, S. (2007). Non-linear dynamics of population and natural resources: The emergence of different patterns of develpment. Ecological Economics, 62(3), 473-481.

- Filippov, A. F. (1988). Differential Equations with Discontinuous Righhand Sides. Springer Netherlands.

- Flores, J. (2015). A phase-transition model for the rise and collapse of ancient civilizations: A preceramic andean case study. Physica A: Statistical Mechanics and its Applications, 155-160.

- Heckbert, S. (2013). Mayasim, An agent-based model of the ancient Maya social-ecological system. Journal of Artificial Societies and social Simulation, $14(4), 11$.

- J. Brander, M. S. (1998). The simple economics of Easter Island: A RicardoMalthus model of renewable resource use. American Economic Review, $88(1), 119-138$.

- S. Roman, S. B. (2018). Coupled societies are more robust against collapse: A hpothetical look at Easter Island. Ecological Economics, 132, 264-278. 